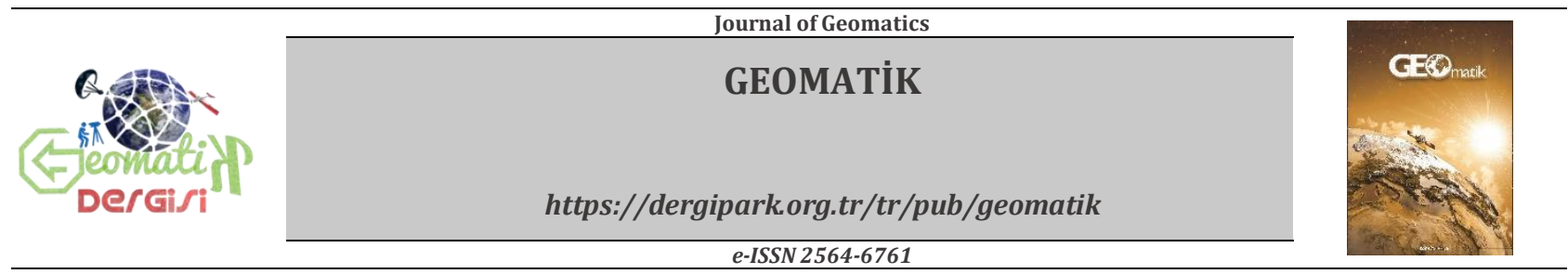

\title{
Çok bantlı Landsat 8-OLI ve Sentinel-2A MSI uydu görüntülerinin karşılaştırmalı jeoloji uygulaması: Örnek çalışma alanı olarak Doğu Anadolu Fayı boyunca Palu - Hazar Gölü bölgesi (Elazı̆̆, Türkiye)
}

\author{
Cengiz Zabcı*1 \\ 1Istanbul Teknik Üniversitesi, Maden Fakültesi, Jeoloji Müh. Bölümü, İstanbul, Türkiye
}

\author{
Anahtar Kelimeler \\ Uzaktan Algilama \\ Jeoloji \\ Landsat-8 \\ Sentinel-2 \\ Doğu Anadolu Fayı
}

\begin{abstract}
ÖZ
Jeoloji haritalarının yapımında, özellikle erişimi zor sahalar için son yıllarda çok bantlı uydu görüntülerinin kullanımı yaygınlık kazanmıștır. Teknolojinin ilerlemesine paralel olarak bu tarz görüntü alan uyduların sayısının yanı sıra, kaydettikleri görüntü kalitesinde de belirgin bir artış olmuştur. Bu çalışma, farklı uzay ajansları tarafından yörüngeye fırlatılarak ișletilen Landsat 8 OLI ve Sentinel 2A MSI uydularına ait uzay görüntülerinin Palu ve Hazar Gölü (Elazığ) arasında kalan bir bölgenin jeolojisi için karşılaștırmasını içerir. Türkiye'nin en önemli deprem kușaklarından Doğu Anadolu Fayı'nın (DAF) yer aldığı bu bölgede kayaç gruplarının hassas olarak belirlenmesi, fayın yakın ve uzun dönem davranışının anlaşılması açısından büyük öneme sahiptir. Her iki veri seti için uygulanan bant kombinasyonu, bant oranlaması, Minimum Gürültü Fraksiyonu (MNF) ve Temel Bileșen Analizi (PCA) işlemleri sonucunda, veri setinden bağımsız olarak bant kombinasyonu ve MNF analizlerinin daha iyi sonuç verdiği görülür. Farklı uydu tiplerinden, jeoloji haritası ile karşılaștırıldıkları zaman, Sentinel 2'ye ait RGB bant kombinasyonu renk zenginliği ile öne çıkar. Açık erişime sahip olan bu uydu görüntülerinin kullanımının, özellikle erişimi zor alanlarda jeolojik harita yapma hassasiyetini arttıracağı bir gerçektir. Bu veri kaynaklarından Sentinel 2A MSI uydusu hem bant zenginliği hem de göreceli yüksek çözünürlügü ile ön plana çıkmaktadır.
\end{abstract}

\section{Comparison of Landsat 8 OLI and Sentinel-2A MSI spaceborn datasets for geological mapping: a case study for the Palu - Hazar Gölü region along the East Anatolian Fault (Elazı̆g, Turkey)}

\author{
Keywords \\ Remote sensing \\ Landsat-8 \\ Sentinel-2 \\ Geology \\ East Anatolian Fault
}

\begin{abstract}
It is an increasing trend to use multi spectral satellite imagery in geological mapping, especially for remote regions. Moreover, the quality and quantity of such satellites have significantly increased parallel to the technological evolution. In the frame of this study, I use and compare multi spectral imagery of Landsat $8 \mathrm{OLI}$ and Sentinel 2A MSI satellites for geological mapping of a region between Palu and Hazar Gölü (Elazığ). This region is also known to host one of the most important earthquake belts of Turkey, the East Anatolian Fault (EAF), thus, it is quite crucial to generate precise geological maps in order to document the long- and short-term kinematics of this fault zone. I processed both data sets by using RGB band combinations, bant ratio, Minumum Noise Fraction (MNF) and Principal Component Analysis (PCA) techniques. The RGB band combination and MNF provide the best results for both Landsat 8 and Sentinel 2 images. When I compare the results of both data sets, the RGB band combination of Sentinel 2 shows the richest image with respect to the geological map of the region. It is quite obvious that multi spectral imagery are powerful tools to increase the precision of geological maps, especially for remote regions. Sentinel 2A MSI imagery is an ideal source for geological mapping with their relatively high resolution and band quality.
\end{abstract}




\section{GíRiş}

Jeolojinin çok disiplinli yapısında, maden aramalarından aktif fay araştırmalarına kadar pek çok farklı çalışmada, jeoloji haritalarının üretilmesi en temel gereklerden biridir. Günümüzde bir jeoloji haritasının yapılmasında en etkili yöntem halen saha çalışmalarıdır. Ancak, son yıllarda coğrafi olarak engebeli ve/veya ulaşımı zor bölgelerde jeoloji haritalarının üretilmesinde çok bantlı uydu görüntülerinin kullanılması yaygınlık kazanmaktadır (ör: Goetz ve Rowan, 1981, Khalifa ve ark., 2020, Peña and Abdelsalam, 2006, Richetti, 2000, Rigol ve Chica-Olmo, 1998, van der Meer ve ark., 2012, Zumsprekel ve Prinz, 2000). Bu görüntülerin sahip olduğu farklı dalga boylarında çok sayıda bantın uzaktan algılama yöntemleri kullanılarak işlenmesi sonucu sadece jeolojik birimlerin değil, aynı zamanda bitki örtüsü dağılımı, tarım alanlarının yayılımı ve diğer benzeri haritalama çalışmalarını yapmak mümkündür (ör: Akar ve Tunç Görmüş, 2019, Apaydın ve Abdikan, 2021, Dilekçi ve ark., 2021, Doğru ve Yücel, 2017, Erdem ve ark., 2018, Erener ve Sarp, 2017, Karip ve Göksel, 2017, Köküm, 2019, Tunay ve Ateşoğlu, 2008). Landsat uydu ailesi (NASA/USGS) ve ASTER (NASA/Japonya Ekonomi Bakanlığı/Japonya Uzay Sistemleri) ürünlerinin yaygınca kullanıldığı bu tip uygulamalara, özellikle son yıllarda Avrupa Uzay Ajansı'nın (ESA) dünya yörüngesine kazandırdığı Sentinel-2 uydusu ile elde edilen görüntülere dayalı çalışmalar da eklenmiştir (Costa ve ark., 2017, Fal ve ark., 2019, Salehi ve ark., 2019, van der Meer ve ark., 2014, van der Werff ve van der Meer, 2015, van der Werff ve van der Meer, 2016).

Bu çalışma, yörüngeye firlatıldığ 11 Şubat 2013 tarihinden bugüne çok sayıda farklı uygulamada karşımıza çıkan Landsat 8 OLI ile 23 Haziran 2015 tarihinden beri çok bantlı görüntü sağlayan Sentinel2A MSI uydularına ait verilerin jeolojik haritalama amacıyla karşılaştırmasını içerir. Karşılaştırma yapılacak yer olarak Palu-Hazar Gölü (Elazığ) arasında kalan bölge seçilmiştir. Bunun ana sebebi, inceleme alanı içerisinde Türkiye'nin en önemli deprem kuşaklarından Doğu Anadolu Fayı'nın (DAF) yer alması ve bu bölgede kayaç gruplarının DAF'ın yakın ve uzun dönem davranışının anlaşılması açısından büyük öneme sahip olması yüzündendir. Bu amaçla, aynı zaman dilimine (Ağustos 2019) ve hemen hemen aynı mekânsal kapsama sahip birer çerçeve Landsat 8 OLI ve Sentinel-2 görüntüsü aşağıda ayrıntıları anlatılan uzaktan algılama yöntemleri ile işlenmiş ve bölgenin bilinen jeoloji haritaları ile karşılaştırılmıştır. $\mathrm{Bu}$ çalışmanın sonuçları sadece Palu ve Hazar Gölü arasında kalan sınırlı bölge için değil, benzer morfojenetik bölgelerde litolojik birimlerin mekânsal dağılımının haritalanmasında karşılaştırmalı bir yöntemin geliştirilmesine katkı sağlayacaktır.

\section{DOĞU ANADOLU FAYI'NIN HAZAR-PALU ARASINDAKİ KESIMII VE BÖLGE JEOLOJISII}

Avrasya, Afrika ve Arabistan levhalarının birbirlerine göre gerçekleştirdikleri yakınlaşma hareketi, daha küçük olan Anadolu Bloğu'nun Avrasya Levhası'na göre batı yönüne doğru kaçmasına sebep olmuştur (McKenzie, 1972, Reilinger ve ark., 2006, Şengör ve ark., 1985,). Bu kaçma hareketi, Anadolu Bloğu'nun kuzey sınırında Kuzey Anadolu Fayı, doğu-güneydoğu sınırında ise Doğu Anadolu Fayı boyunca gerçekleşir (Barka ve Reilinger, 1997, Şengör, 1980, Şengör ve ark., 1985).

Türkiye'nin en önemli deprem kuşaklarından birini oluşturan Doğu Anadolu Fayı (DAF), kuzeydoğuda Karlıova (Bingöl), güneybatıda ise Türkoğlu (Kahramanmaraş) arasında yaklaşık 450 $\mathrm{km}$ uzunluğa sahip sol yanal doğrultu atımlı karakterde bir tektonik yapıdır (Dewey ve ark., 1986, Gülen ve ark., 1987). DAF'ın güneybatı yönünde İskenderun Körfezi'ne kadar uzandığı yönünde görüşler de mevcuttur (ör: Herece, 2008, Yönlü ve ark., 2017). Farklı geometrik ve kinematik özelliklere sahip fay parçalarından oluşan DAF, en son 24 Ocak 2020 Mw 6.8 Sivrice (Elazığ) depremi ile bölge için ne denli bir doğal tehlike unsuru olduğunu bizlere bir kez daha hatırlatmıştır.

$\mathrm{Bu}$ çalışmanın odaklandığı bölge, Duman ve Emre (2013)'nin sinıflandırmasına göre DAF'ın Palu Segmenti üzerinde, Palu İlçesi ile Hazar Gölü arasında kalan alan üzerindedir (Șekil 1). Bu bölge için saha çalışması tabanlı hazırlanmış jeoloji haritalarında en altta ağırlıklı olarak PalaeozoyikMesozoyik zamana ait metamorfik kayaçlar görülür. Genel olarak şistler, mermerler ve metavolkaniklerden oluşan bu grubun üzerinde, Mesozoyik'te Neotetis Okyanusu'nun kapanmasiyla ilişkili olarak oluşan (Şengör ve ark., 2019) ve ofiyolit stratigrafisinin farklı kesimlerine karşılık gelen gabro, bazalt ve peridotit gibi mafik-ultramafik kayaç toplulukları yer alır. Bu birimlerin arasında yer alan sedimanter topluluklar ofiyolit stratigrafisinin en üst kesimlerine aittir. Neotetis Okyanusu'nun kapanmasını takiben oluşan Senozoyik seri Eosen zamanında kırıntılı ve karbonatlı kayaçların yanı sıra volkanik serilerle temsil edilirken, Eosen - Miyosen zaman aralığı denizel-sığ denizel ve karasal ortamda oluşan karbonatlı ve kırıntı kayaçları içerir. Bütün bu birimler Pliyo-Kuvaterner yaşlı farklı flüvyal fasiyeslerde oluşmuş kırıntılı çökel paketleri ile uyumsuz bir şekilde örtülür (Herece, 2008, Kesin, 2011a, Keskin, 2011b, Sümengen, 2011a, Sümengen, 2011b). Bu birimlerin birbirlerinden ayırt edilmesi, özellikle ofiyolitik kayaçların fay davranışı üzerinde (ör: asismik kayma hareketini tetiklemesi gibi) bilinen etkisi açısından (Kaduri ve ark., 2017) ve bölgenin deprem tehlikesinin ortaya konmasında büyük öneme sahiptir. 


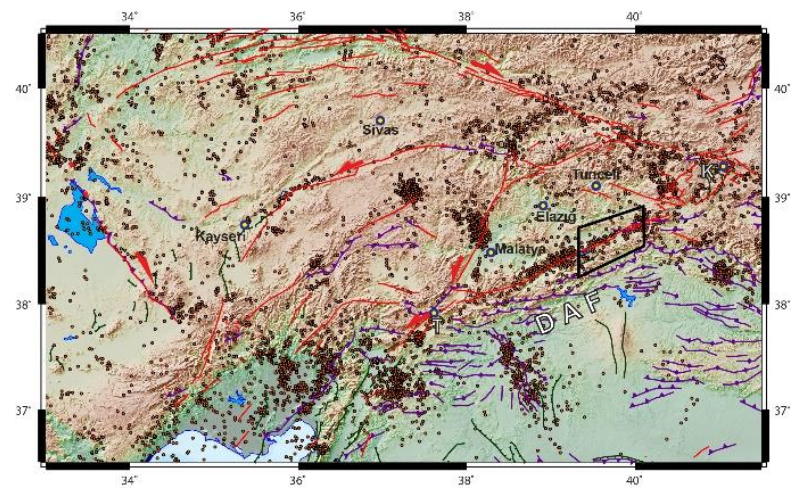

Şekil 1. Orta-Doğu Türkiye'nin neotektonik fayları (Şengör ve Zabcl, 2019) ve aletsel dönem depremleri (Kandilli Rasathanesi ve Deprem Araștırma Enstitüsü, 2020). Türkiye'nin en önemli deprem kuşaklarından birini oluşturan Doğu Anadolu Fayı (DAF), kuzeydoğuda Karlıova (K) ile güneydoğuda Türkoğlu (T) arasında yaklaşık $450 \mathrm{~km}$ uzunluğa sahiptir. Bu çalıșmanın coğrafi kapsamı siyah dörtgenle gösterilmiștir

\section{MATERYALLER VE YÖNTEM}

Landsat 8 OLI ve Santinel-2A MSI, sirasiyla 2013 ve 2015 yllarından itibaren yörünge yolculukları boyunca düzenli çok bantlı görüntü verisi sağlayan uydulardır. İki uydu birlikte değerlendirildiğinde, her 3 günde bir küresel ölçekte veri alımı gerçekleştirir (van der Werff ve van der Meer, 2016). $\mathrm{Bu}$ uyduların, alıcı özellikleri karş̧laştırıldığında, Landsat 8'in farklı dalga boylarında toplam 11, Sentinel-2'nin ise 13 adet bant içerdiği görülür (Şekil 2).

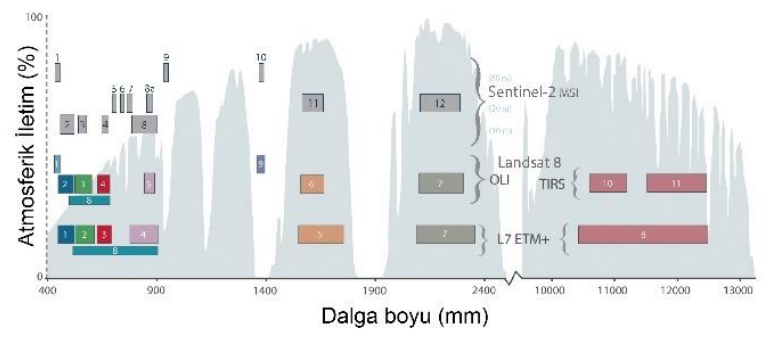

Şekil 2. Sentinel-2 ve Landsat 7-8 uydularının sahip olduğu bantların eni, dalga konumları ve sayılarının karşılaștırma grafiği. USGS'den Türkçeleştirilerek alınmıştır

Jeolojik birimlerin ayırt edilmesinde iki farklı uydu görüntüsünün karşılaştırılmasını hedefleyen bu çalışma çerçevesinde, atmosfer koşulları ve bitki örtüsünün birbirlerine en yakın durumda olduğu mümkün olduğunca benzer zaman dilimlerine ait çerçevelerin kullanılmasına özen gösterilmiştir. Bu doğrultuda Landsat 8 OLI için 8 Ağustos 2019, Sentinel 2A MSI içinse 16 Ağustos 2019 tarihinde alınan veriler işlenmiştir.

Açık erişimli Birleşik Devletleri Jeoloji Kurumu (USGS) ve Avrupa Uzay Ajansı (ESA) sunucularından ücretsiz olarak tedarik edilen bu görüntülerin işlenmesinde; Landsat 8 için sadece ENVI 5.3, Sentinel-2 için ise aynı yazılıma ek olarak gene ESA tarafından geliștirilen SNAP programı kullanılmıștır. Bütün işlemler sonucunda elde edilen görüntülerin düzenlenmesi, derleme jeoloji haritasının çizilmesi ve şekillerin son hali QGIS ile gerçekleştirilmiştir. Bütün bu ișlemlerin özetini içeren akış şeması Şekil 3'te görülebilir.

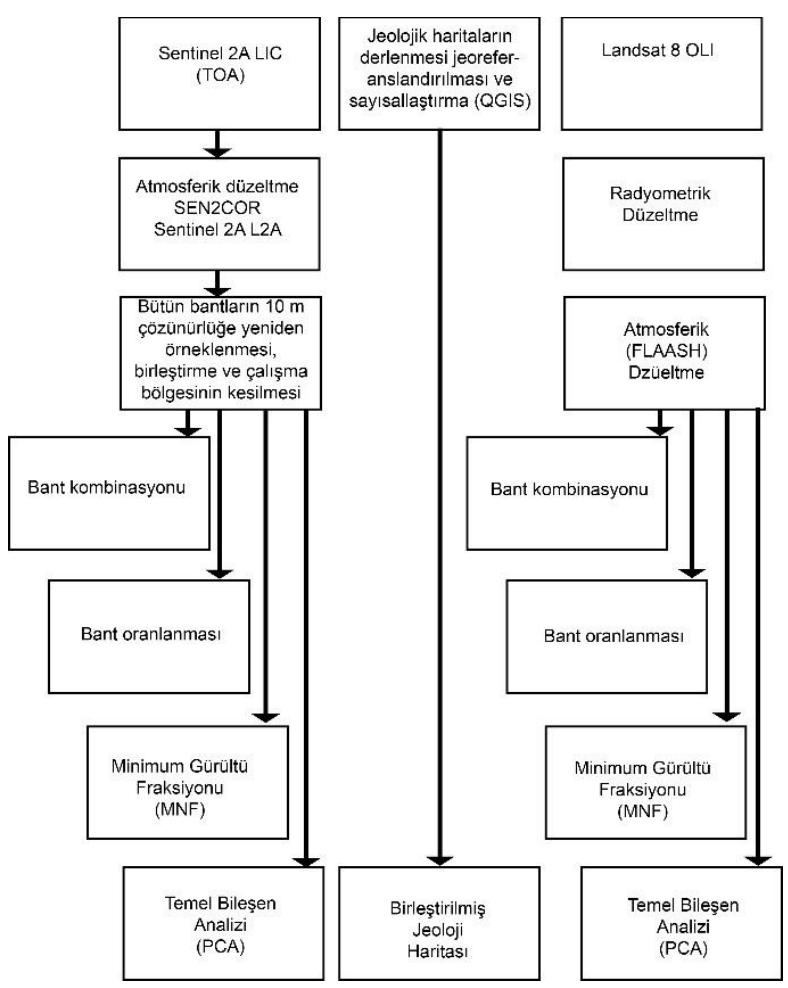

Şekil 3. Bu çalıșmada uygulanan yöntemler için izlenen akış şeması

\section{1. Ön İşleme}

Ham Sentinel 2A MSI görüntüsünün atmosfer üstü (TOA) haline ait granüller, SNAP yazılımına eklenti olarak çalışan SEN2COR paketi kullanılarak geometrik ve atmosferik düzeltmeden geçirilmiş ve L2A veri seti üretilmiştir. Bu yeni veri setinde $20 \mathrm{~m}$ çözünürlüğündeki bantlar $(5,6,7,8 a, 11$ ve 12$)$ en yakın komşu yöntemi ile $10 \mathrm{~m}$ piksel çözünürlüğüne yeniden örneklenmiştir. Yeni Sentinel 2 L2Averi seti, bütün bantları ile birlikte ENVI 5.3 ile işlenmek üzere Geotiff olarak dışa aktarılmıştır. Benzer şekilde Lansat 8 OLI çerçevesi, ENVI 5.3 yazılım paketinin sahip olduğu araçlar ile önce geometrik ve radyometrik, daha sonra da FLAASH (Hızlı görüş hattı hiper küplerinin atmosferik analizi) atmosfer düzeltme işlemine tabi tutulmuştur. En son aşamada hem Sentinel 2 hem de Landsat 8 veri setleri, inceleme alanı olarak DAF boyunca belirlenen ortak dörtgen kullanılarak kesilmiş ve işlem aşamasına hazır hale getirilmiştir.

Uydu görüntülerinin ön işlemine ek olarak, kâğıt baskı halinde 1:100000 ölçekli jeoloji haritaları taranarak sayısallaştırılmış ve daha sonra jeoreferanslandırma işleminden geçirilmiştir. Dört farklı jeoloji haritası kullanıldığı bu işlem sonrası, 
Palu ve Hazar Gölü arasında, belirli bir çerçeve içerisinde jeoloji formasyonları QGIS kullanılarak VEKTÖR'leștirilmiştir. Bu vektör dosyası için bir öznitelik tablosu hazırlanmış ve buna birim sembolleri ve adları gibi temel bilgiler girilmiştir.

\section{2. İşleme}

Ön işlem süreci sonunda geometrik, radyometrik ve atmosferik düzeltmeden geçirilen Landsat 8 ve Sentinel 2 veri setleri, farklı jeoloji formasyonlarının görselleştirilmesi amacıyla sırasıyla ENVI 5.3 yazılım paketinin araçları arasında bulunan bant kombinasyonu, bant oranlarl, Minimum Gürültü Fraksiyonu (MNF) ve Temel Bileşen Analizi işlemlerinden geçirilmiştir. Bu işlemlerin nasıl gerçekleştirildiği her bir veri seti için aşağıda alt başlıklar altında kısaca anlatılmıştır.

\subsubsection{Bant Kombinasyonları}

Çok bantlı uydu görüntülerinde farklı bantların RGB kombinasyonları bilinen en temel görüntü zenginleştirme araçlarından biridir (ör: Loughlin and Tawfiq, 1985, Novak ve Soulakellis, 2000, Rothery, 1987). Özellikle Landsat uydu verileri ile ilgili yapılan uygulamalarda çok sayıda standart bant kombinasyonu, amaca yönelik olarak kullanılmaktadır. Bu çalışmada Chavez ve ark. (1982) tarafından geliştirilen, en yüksek bilgi ve en düşük tekrarlama içeren bantların tespit edilmesine dayalı Optimum İndeks Faktörü (OIF) kullanılmıştır. OIF'de optimum bant kombinasyonu, bantlarin standart sapması ve bantlar arası korelasyon katsayısına göre belirlenmektedir. Buna göre genellikle en çok bilgi içeren bantlar en düşük korelasyona ve büyük spektral çeşitliliğe sahip olanlardır. Bantların bütün üçlü kombinasyonları içerisinde en optimum olanı, en yüksek toplam standart sapmaya ek olarak en düşük duplikasyon miktarına sahip olan bantlardan oluşur.

$\mathrm{Bu}$ çalışmada akademik kullanımı serbest olan ILWIS yazılımı ile sırasıyla; (a) olası bütün bant kombinasyonlarının belirlenmesi, (b) aşağıda belirtilen denklem (1) kullanılarak her kombinasyon için OIF'nin hesaplanması ve (c) bütün RGB kombinasyonlarının OIF değerlerine göre sıralanmasını içeren otomatik adımlar uygulanmıştır.

$$
O I F=\frac{\sum_{k=1}^{3} S_{k}}{\sum_{j=1}^{3} A b s\left(r_{j}\right)}
$$

Bu denklemde $S_{k}$, k bantı için standart sapmayı, $r_{j}$ ise korelasyon katsayısı için mutlak değeri temsil eder.

En yüksek OIF'in genelde en bilgi verici bant kombinasyonu olduğu kabul edilir. Buna göre, Landsat 8 veri seti için elde edilen en yüksek OIF değerine sahip bant kombinasyonu sırasıyla 7, 5 ve 1 (SWIR 2, Yakın kızıl ötesi ve kıyı aerosol) iken,
Sentinel 2 için 8a, 10 ve 2 (Dar yakın kızıl ötesi, SWIR ve Mavi) olarak hesaplanmıştır.

\subsubsection{Bant oranları}

Bant oranı, bir bantın sahip olduğu sayısal değerin diğer bir banta ait değere oranlanması sonucu elde edilir. Bu teknik özellikle ham bantların görüntü zenginleştirmesinde yeterli kalmadığı durumlarda işe yarar (ör: Inzana ve ark., 2003, Mars ve Rowan, 2011, Rockwell ve Hofstra, 2008).

Landsat 8 ve Sentinel 2 görüntüleri ayrı veri setleri olarak değerlendirilip, farklı bant oranlarına tabi tutulmuşlardır. Buna göre, Landsat 8 için 4/3, $6 / 2$ ve 7/4 (Kırmızı/Yeşil, SWIR 1/Mavi ve SWIR 2/Kırmızı), Sentinel 2 için ise van der Werff ve van der Meer (2016) tarafindan önerilen 11/12, 4/2, 4/11 oranları ile zenginleştirme işlemi yapılmıştır.

\subsubsection{Minimum Gürültü Fraksiyonu (MNF)}

Minimum Gürültü Fraksiyonu (MNF) çok sayıda banttan oluşan bir görüntüde, en çok bilgi taşıyanların belirlenmesi için kullanılan etkili bir transformasyon aracıdır. Bu teknik temelde, Green ve ark. (1988)'in art arda bağlanmış iki Temel Bileșen Analizi (PCA) transformasyonuna dayanır. İlk olarak gürültü kovaryans matrisinin kestirimine dayalı transformasyon uygulaması ile veride korelasyon kaldırılarak, gürültü yeniden ölçeklendirilir. İkinci aşamada ise standart PCA transformasyonu ile gürültü azaltılır. $\mathrm{Bu}$ çalışma kapsamında Landat 8 ve Sentinel 2 veri setleri, ENVI yazılımının standart MNF aracıyla işlenerek sonuç elde edilmiştir.

\subsubsection{Temel Bileşen Analizi (PCA)}

Temel Bileşen Analizi (PCA), çok bantlı görüntülerde değişiklikleri yeniden düzenleyerek yeni görüntü bantlarından oluşan bir veri setinin üretilmesini sağlayan transformasyon tekniğidir. Bu çalışmada kullanılan ENVI yazılımı PCA transformasyonu için sırasıyla; (a) Girilen görüntüde kovaryans ve korelasyon matrislerinin hesaplanması, (b) Kovaryans ve korelasyon matrisleri kullanılarak öz değer vektörlerinin hesaplanması, (c) Girilen görüntülerden bant ortalamalarının çıkartılması ve (d) Richards (1999)'un yaklaşımı kullanılarak ortalamalar ile düzeltilmiş şekillerin dönüştürülmesi işlemlerini içerir. ENVI 5.3 ile otomatik olarak gerçekleştirilen bu işlem, ayrı ayrı Landsat8 ve Sentinel 2 veri setlerine uygulanmıştır.

\section{BULGULAR}

Dört farklı yöntem kullanılarak ișlenen Landsat 8 ve Sentinel 2 veri setlerinden elde edilen sonuçlar, karşılaştırmalı olarak Şekil 4'te sunulmuştur. 

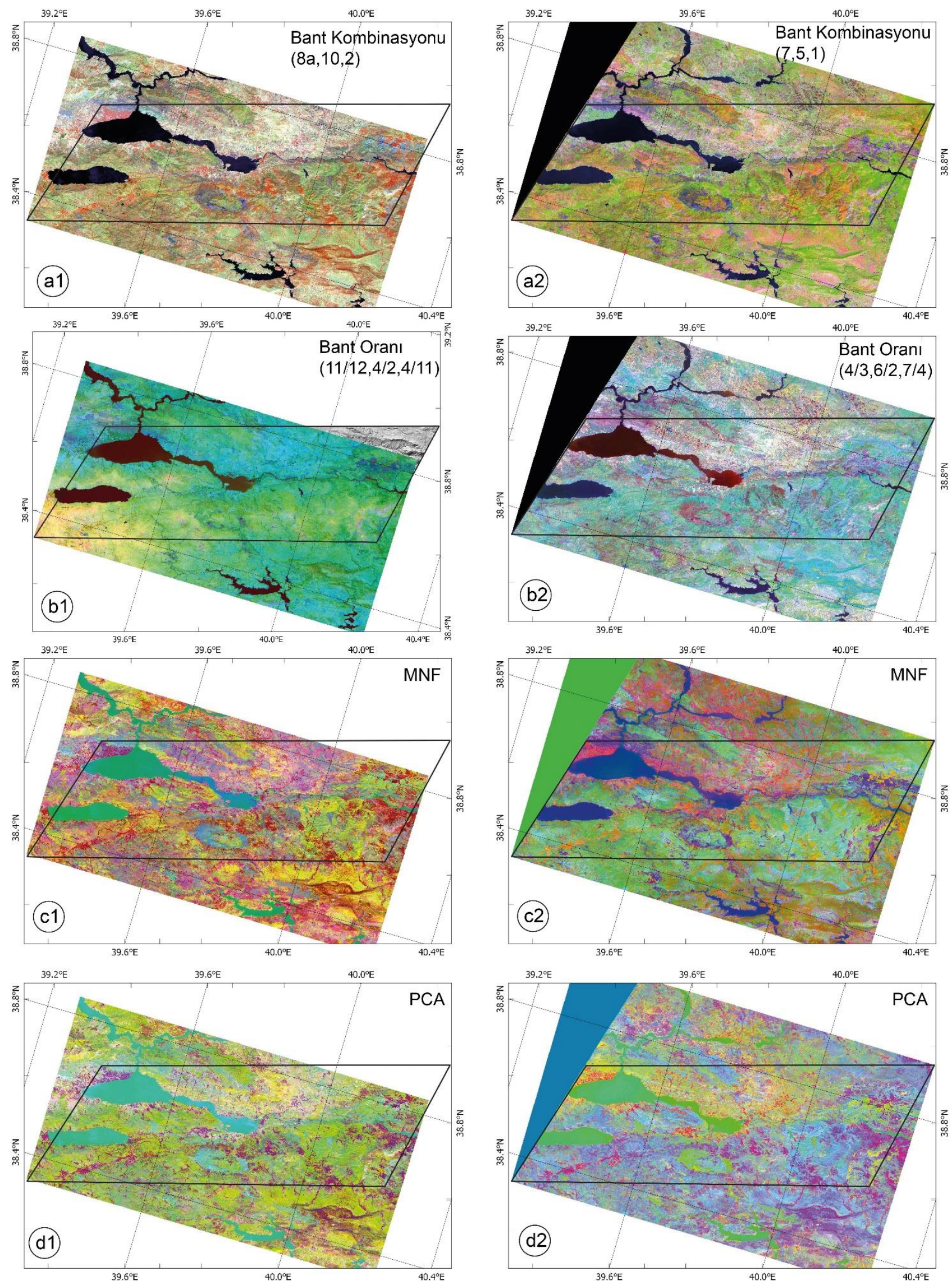

Șekil 4. Sentinel 2 MSI ve Landsat 8 OLI veri setlerinin farklı teknikler kullanılarak elde edilen sonuçlar. Sol sütun Sentinel -2, sağ sütun ise Landsat 8 veri setine dayalı sonuçları gösterir. Her teknik için kullanılan özel bant numaraları şekillerin üzerinde belirtilirken (Bant kombinasyonu ve bant oranı için), siyah çerçeve incelenen alanı temsil eder: (a) Bant kombinasyonu, (b) Bant oranı, (c) Ortalama Gürültü Fraksiyonu, (d) Temel Bileșen Analizi 
Elde edilen sonuçlar incelendiği zaman, hangi uyduya ait görüntü kullanılırsa kullanılsın, Bant kombinasyonu ve MNF sonuçlarının çok daha zengin sonuçlar verdiği görülür (Şekil 4a ve c). Farklı veri setleri kendi aralarında karşılaştırıldığında, Sentinel 2'nin Landsat 8 sonuçlarına göre hem bant kombinasyonunda hem de MNF'de yüksek kontrastı ile öne çıkar. Ancak Landsat 8 veri seti bant oranı ve PCA görüntülerinde belirgin bir şekilde daha çok renk sunar. Sentinel-2 veri setinin münferit kullanım alanlarında farklı bant oranlarının tercih edilmesi durumunda daha zengin sonuçlar elde edilmesi büyük olasılığa sahiptir.

Şekil 4a1'de gösterilen ve Sentinel 2 uydusunun sirasıyla $8 \mathrm{a}, 10$ ve 2 bantlarının RGB kombinasyonu ile elde edilen görüntü, derlenen jeoloji haritası göz önünde bulundurulduğu zaman en zengin sonuç olarak öne çıkar (Șekil 5). Bu görüntüde, düzensiz bir şekilde saçılmış kırmızı-kırmızımsı turuncu (RGB 228/71/29) renkli alanlar sınırlı mekânda yayılıma sahip zaylf orman örtüsünü gösterirken, genelde dörtgen poligonlar halinde pembe/kırmızı $(232,65$, 65 ve $222 / 227 / 244)$ ve açik yeşil $(181 / 218 / 195)$ kolajından oluşan kesimler alüvyon üzerindeki tarım alanlarını gösterir. Bunların dişında kalan kesimlerde ise özellikle yeşil ve mavi'nin tonları farklı litolojik birimleri temsil etmektedir. Örneğin, mor (112/116/178) ve tonları Guleman Ofiyoliti'nin (Şekil 5'te Kg) mafik ve ultramafik kayaçlarını gösterirken, çalışma alanının doğu-kuzeydoğusunda açık mavi renk (150/193/227) gösteren alan Kırkgeçit Formasyonu'nun (Teok) karbonatlı kayaçlarına karşıllk gelir. Hatta bu ve diğer karakteristik renk tonlarının dağlımı göz önünde bulundurulduğu zaman, jeoloji haritasının arazi ulaşımı güç kesimlerinden bir kısmının daha ayrıntılı haritalanabileceği görülür. Bu bağlamda Șekil 5a ve $5 \mathrm{~b}$ ayrı ayrı incelendiği zaman, Guleman Ofiyoliti $(\mathrm{Kg})$ olarak $39.8^{\circ} \mathrm{D}$ boylamında, $38.4^{\circ} \mathrm{K}$ ve $38.5^{\circ} \mathrm{K}$ enlemleri arasında oldukça geniş bir alanı kapsadığını, ama Sentinel 2 bant kombinasyonunda bu kesimin farklı renklere sahip litolojilerle temsil edildiği dikkati çeker. Benzer șekilde farklı renklerin yarattığı kontrast, birim sınırlarının daha hassas çizilmesi için ideal bir araç özelliği görür. Özel olarak seçilen bir alt alan bu perspektifte incelendiği zaman, özellikle Kg biriminin Sentinel 2 bant kombinasyonu üzerinde belirgin mor rengi sayesinde, komşu jeolojik birimlerle sahip olduğu sınırın daha ayrıntılı çizilebileceği açıtıtır (Şekil 6).
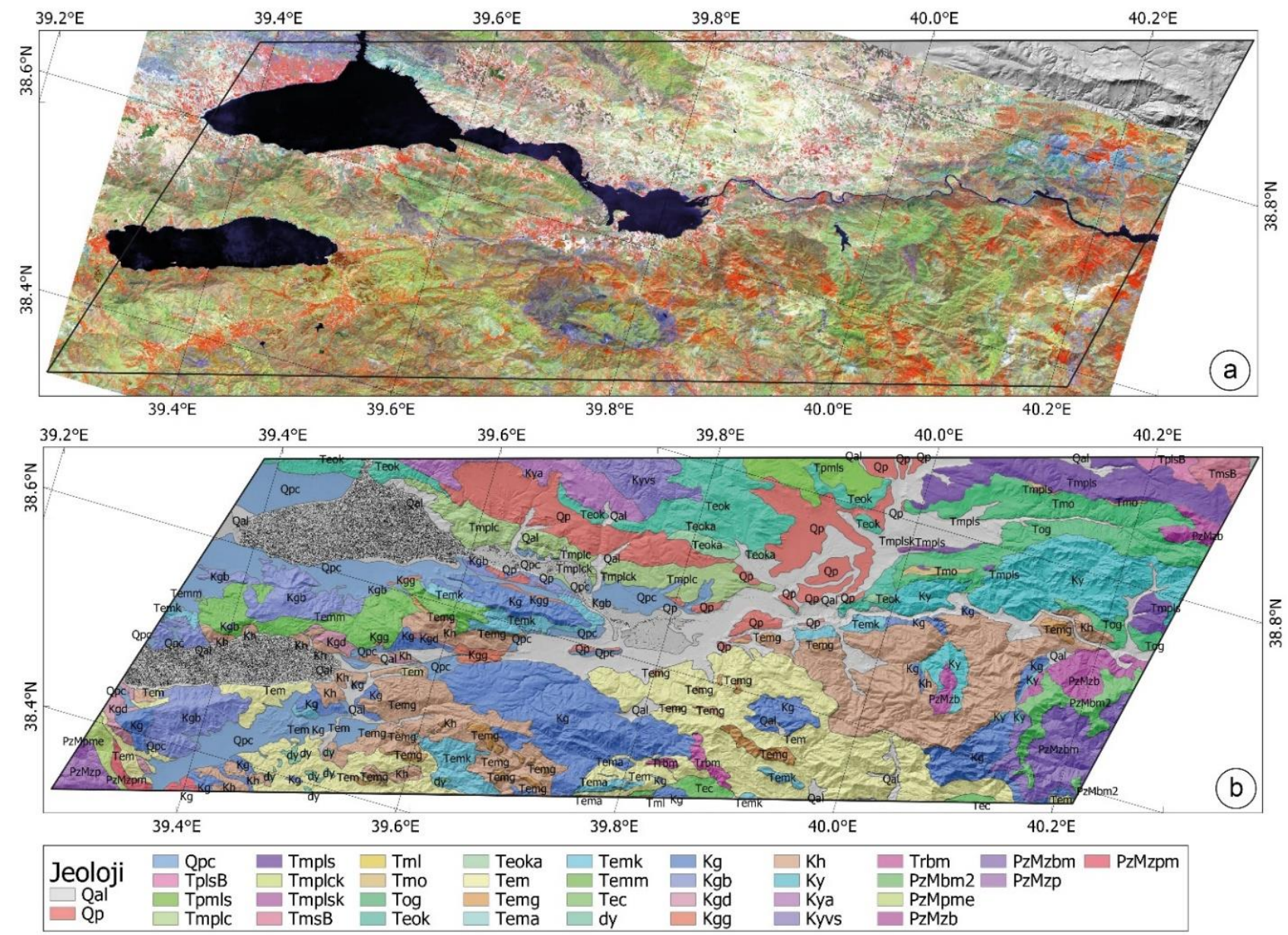

Şekil 5. (a) İşlenen veri setleri arasında inceleme alanı jeolojisi açısından en zengin görüntüyü sunan Sentinel 2 RGB bant kombinasyonu ve (b) Bölgenin saha çalışmalarına dayalı olarak üretilen derleme jeoloji haritası (Herece, 2008, Kesin, 2011a, Keskin, 2011b, Sümengen, 2011a, Sümengen, 2011b). Jeolojik birimler, bu çalışma açısından önem taşımadığı için sadece sembollerle gösterilirken, birim renkleri için jeoloji zaman çizelgesi kullanılmamıştır 


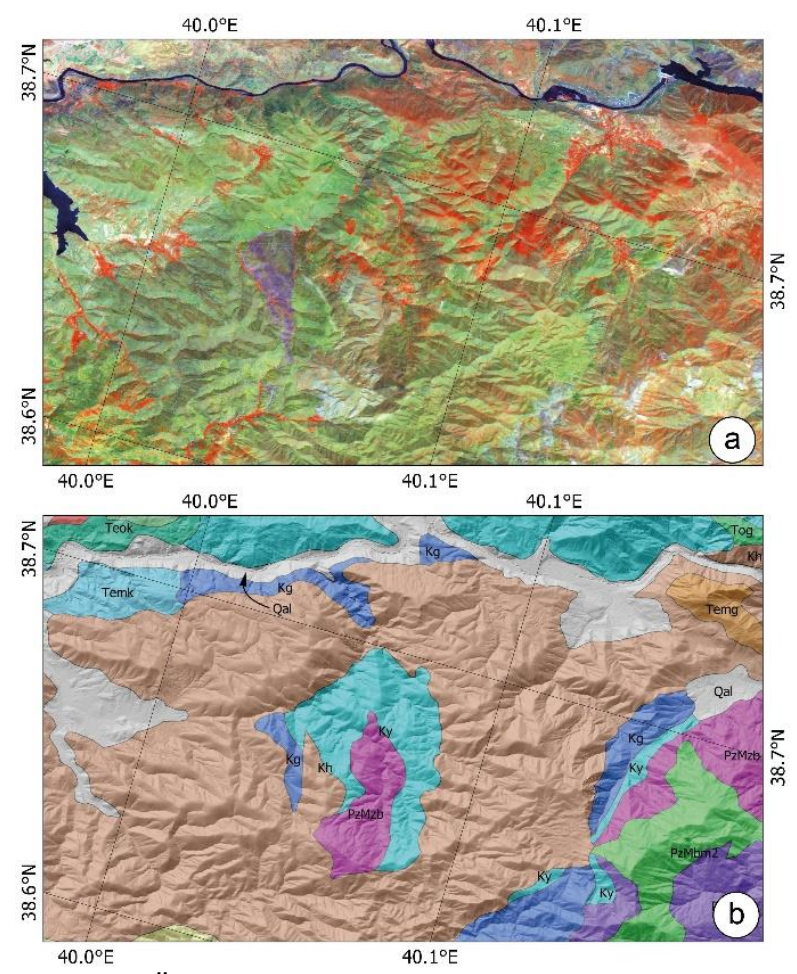

Şekil 6. Özel seçilmiş bir alt alanın (a) Sentinel 2 bant kombinasyonu ve (b) saha çalışmalarına dayalı jeoloji haritaları. Mor rengi ile dikkati çeken $\mathrm{Kg}$ biriminin sınırlarının Sentinel 2 görüntüsü üzerinde çok daha belirgin olup diğer jeolojik birimlerle sahip olduğu sınırın daha ayrıntılı çizilebileceği açıktır

\section{SONUÇLAR}

Palu ve Hazar Gölü (Elazığ) arasında özel olarak seçilen çalışma alanı için ayrı ayrı Landsat 8 OLI ve Sentinel 2A MSI uydu görüntüleri kullanılarak bölgenin jeolojik birimlerinin dağılımı çalıșılmıștır. RGB bant kombinasyonu, bant oranı, Minimum Gürültü Fraksiyonu (MNF) ve Temel Bileşen Analizi (PCA) işlemlerinin arasından en iyi sonuçları uydu kökeninden bağımsız olarak bant kombinasyonu ve MNF yöntemleri vermiştir. İki uydu veri seti karşılaştırıldığındaysa Sentinel 2, renk kontrastı ve mevcut jeoloji haritasiyla gösterdiği uyumla öne çıkar.

En iyi sonucu veren Sentinel 2 RGB bant kombinasyonuna göre, bölgede seyrek ormanlık alanlar kırmızı renkle belirgindir. Genelde farklı ofiyolit seviyelerinden oluşan jeolojik birimler, renk kontrastları ile açık bir şekilde görülmektedir. Özellikle çalışma alanının yüksek rölyefli kesimlerinde, jeolojik birim sınırlarının bu veri seti kullanılarak daha ayrıntılı çizilebileceği görülür.

Elde edilen diğer bir sonuç ise, bölgenin deprem kaynağı olan Doğu Anadolu Fayı ve yersel kayaç gruplarının ilişkisidir. Bölgede gerçekleştirilen jeodezik çalışmalar (Küresel Navigasyon Uydu Sistemi - GNSS ve Interferomektrik Yapay Açıklıklı Radar - InSAR), fayın bu kesiminin neredeyse bütün tektonik yüklemeyi asismik krip hareketi ile karşıladığını göstermektedir (Çakır ve ark., 2018, Çetin ve ark., 2016, Doğan ve ark., 2019, Ergintav ve ark., 2017). Dünyanın farklı yerlerinde yapılan çalışmalar sonucu, bu asismik krip hareketinin özellikle ofiyolitik kayaçların ağırlıkta olduğu kesimlerde gerçekleștiği bilinen bir gerçektir (ör: Kaduri ve ark., 2017). Sentinel 2 bant kombinasyonunda mor renkle belirlenen ve Guleman ofiyolitini temsil eden alanların, krip hareketinin en belirgin görüldüğü Palu - Hazar Gölü kesiminde, DAF boyunca yayılım göstermesi, kayaç toplulukları ile bu asismik davranış biçiminin mekânsal dağılımı arasında önemli bir bulgudur.

Özetle açık erişime sahip çok bantlı uydu görüntülerinin giderek yaygınlaşan kullanımları, jeoloji haritalarının üretilmesi ve revizyonunda önemli bir yere sahiptir. Özellikle erişimi zor uzak yerlerde, olası olarak çizilmiş sınırların düzeltilmesi/hassasiyetinin arttırılması için bu veri gruplarından faydalanılabilir. $\mathrm{Bu}$ çalışmada karşılaştırılarak kullanılan veri setleri arasından Sentinel 2 görüntüsü, göreceli yüksek çözünürlüğü ve sağladığı zengin bant kombinasyonu ile öne çıkarak benzer morfojenetik bölgeler için potansiyel taşıdığını göstermiştir.

\section{BİLGILLENDIRME/TEŞEKKÜR}

$\mathrm{Bu}$ çalışma TÜBITTAK 118Y429 no'lu proje kapsamında gerçekleştirilmiştir. Birinci şekil, açık kaynak kodlu bir yazılım olan 'Generic Mapping Tools' kullanılarak hazırlanmıștır (Wessel ve ark., 2013).

\section{ÇATIŞMA BEYANI}

Herhangi bir çıkar çatışması bulunmamaktadır.

\section{KAYNAKÇA}

Akar, Ö ve Tunç Görmüş, E. (2019). Göktürk-2 ve Hyperion E0-1 uydu görüntülerinden rastgele orman sinıflandırıcı ile arazi kullanım haritalarının üretilmesi, Geomatik Dergisi, 4(1), 68-81.

Apaydın, C. ve Abdikan, S. (2021). Findık bahçelerinin Sentinel-2 verileri kullanılarak piksel tabanlı sınıflandırma yöntemleriyle belirlenmesi, Geomatik Dergisi, 6(2), 107-114.

Barka, A.A. ve Reilinger, R. (1997). Active Tectonics of the Eastern Mediterranean Region: deduced from GPS, neotectonic and seismicity data. Ann. di Geofis. XL, 587-610.

Chavez, P., Berlin, G. L. ve Sowers, L. B. (1982). Statistical method for selecting Landsat MSS, Journal Appl. Photogt. Eng., 8, 23-30.

Costa, S., Santos, V., Melo, D. ve Santos, P. (2017). Evaluation of Landsat 8 and Sentinel-2A data on the correlation between geological mapping and NDVI, First International Symposium on Geosicence and Remote Sensing, 15-16 Haziran 2017, Valdivia, Şili.

Çakır, Z., Ergintav, S., Çetin, S., Şentürk, S., Özdemir, A., Doğan, U., Karabulut, H., Şaroğlu, F., Dikmen, U., Bilham, R. G., Julaiti, W. ve Özener, H. (2018). 
Surface creep along the East Anatolian Fault, American Geophysical Union, Fall Meeting 2018, Abstract \#T51J-0332

Çetin, S., Ergintav, S., Doğan, U., Çakır, Z., Şentürk, S., Karabulut, H., Şaroğlu, F., Julaiti, W. ve Özener, H. (2016). Investigation of the Creep Along the Hazar - Palu Section of the East Anatolian Fault (Turkey) Using InSAR and GPS Observations, EGU General Assembly 2016, 17-22 Nisan, 2016, Viyana Avusturya, EPSC2016-3938.

Dewey, J. F., Hempton, M. R., Kidd, W. S. F., Şaroğlu, F. ve Şengör, A. M. C. (1986). Shortening of continental lithosphere: the neotectonics of Eastern Anatolia -- a young collision zone. Geol. Soc. London, Spec. Publ., 19, 1-36.

Dilekçi, S., Marangoz A., M. Ve Ateşoğlu, A., 2021, Zonguldak ve Ereğli orman işletme müdürlükleri orman yangını risk alanlarının belirlenmesi, Geomatik Dergisi, 6(1), 44-53.

Doğan, U., Ergintav, S., Zabcl, C., Özarpacl, S., Özdemir, A., Erkoç, M. H., Yazıcı, M., Yiğitoğlu, A., Çakır, Z., Karabulut, H., Köküm, M., Bayram, B. Ve Bilham, R. (2019). Investigating the characteristic properties of creeping along the Hazar-Palu Segment of the East Anatolian Fault, Turkey, AGU Fall Meeting, San Francisco, T53C-07.

Doğru, M. ve Yücel, M. A. (2017). LANDSAT 8 OLI Multispektral verileri kullanılarak litolojik harita yapımı, Afyon Kocatepe Üniversitesi Fen ve Mühendislik Bilimleri Dergisi, 17, 172-184.

Duman, T. Y. ve Emre, Ö. (2013). The East Anatolian Fault: geometry, segmentation and jog characteristics. Geol. Soc. London, Spec. Publ., 372, 495-530.

Erdem, F., Derinpınar, M. A., Nasırzadehdizaji, R., Oy, S., Şeker, D. Z. ve Bayram, B. (2018). Rastgele orman yöntemi kullanılarak kıyı çizgisinin çıkarımı İstanbul örneği, Geomatik Dergisi, 3(2), 100-107.

Erener, A. ve Sarp, G. (2017). Barajların çevresel etkilerinin zamansal ve mekânsal olarak uzaktan algılama ile değerlendirilmesi: Atatürk Baraj örneği, Geomatik Dergisi, 2(1), 1-10.

Ergintav, S., Çakır, Z., Doğan, U., Çetin, S., Şentürk, S., Karabulut, H., Şaroğlu, F., Dikmen, Ü., Bilham, R., Özdemir, A., Julaiti, W. ve Özener, H. (2017). Aseismic slip and surface creep on the Hazar-Palu section of the East Anatolian Fault, Turkey, AGU Fall Meeting: New Orleans, AGU.

Fal, S., Maanan, M., Baidder, L. ve Rhinane, H. (2019). The contribution of Sentinel-2 satellite images for geological mapping in the South of Tafilalet basin (Eastern Anti-Atlas, Morocco), The International Archives of the Photogrammetry, Remote Sensing and Spatial Information Sciences, XLII4/W12, 75-82.

Green, A. A., Berman, M. Switzer, P. ve Craig, M. D. (1988). A transformation for ordering multispectral data in terms of image quality with implications for noise removal. IEEE Transactions on Geoscience and Remote Sensing, 26(1), 65-74.
Goetz, A. F. H. ve Rowan, L. C. (1981). Geologic remote sensing, Science, 211(4484), 781-791.

Gülen, L., Barka, A. ve Toksöz, M. (1987). Continental collision and related complex deformation: Maras Triple Junction and surroundin structures, SE Turkey, Yerbilimleri, 14, 319-336.

Herece, E. (2008). Doğu Anadolu Fay (DAF) Atlası, Special Publication Series-13.

Inzana, J., Kusky, T., Higgs, H. ve Tucker, R. (2003). Supervised classifications of Landsat TM ban ratio images and Landsat TM band ratio image with radar for geological interpretations of central Madagascar, Journal of African Earth Sciences, 37, 59-72.

Kaduri, M., Gratier, J.-P., Renard, F., Çakır, Z. ve Lassare, C. (2017). The implications of fault zone transformation on aseismic creep: Example of the North Anatolian Fault, Turkey. Journal of Geophysical Research - Solid Earth, 122, 42084236.

Karip, A. G. B. ve Göksel, Ç. (2017). İğneada koruma alanının arazi örtüsü/arazi kullanımının zaman bağlı değişiminin markov zincirleri ile modellenmesi, Geomatik Dergisi, 2(2), 94-105.

Keskin, İ. (Derleyen) (2011a). Elazığ - L42 paftası jeoloji haritası. Maden Tetkik ve Arama Genel Müdürlüğü, Ankara.

Keskin, İ. (Derleyen) (2011b). Elazı̆̆ - L43 paftası jeoloji haritası. Maden Tetkik ve Arama Genel Müdürlüğü Ankara.

Khalifa, A., Çakır, Z., Kaya, Ş. Ve Gabr, S. (2020). ASTER spectral band ratios for lithological mapping: a case study for measuring geological offset along the Erkenek Segment of the East Anatolian Fault Zone, Turkey, Arabian Journal of Geosciences, 13, 832.

Köküm, M. (2019). Landsat TM görüntüleri üzerinden Doğu Anadolu Fay Sistemi'nin Palu (Elazığ)-Pütürge (Malatya) arasındaki bölümünün çizgisellik analizi, Gümüşhane Üniversitesi Fen Bilimleri Enstitüsü Dergisi, 9(1), 119-127.

Loughlin, W. P. ve Tawfiq, M. A. (1985). Discrimination of rock types and aleration zones from airborne MSS data: the Samram-Shayban and Mahd Adh Dhahab areas of Saudi Arabia, Proceedings of the International Symposium on Remote Sensing of Environment, 4th Thematic Conference, Remote Sensing for Expoloration Geology held in San Fransico, California, 1-4 Nisan 1985, 207-217.

Mars, J. C. ve Rowan, L. C. (2011). ASTER spectral analysis and lithologi mapping of the Khanneshin carbonate volcano, Afghanistan, Geosphere, 7, 276-289.

McKenzie, D. (1972). Active Tectonics of the Mediterranean Region, Geophys. J. R. Astron. Soc., 30, 109-185.

Novak, I. D. ve Soulakellis, N. (2000). Identifying geomorhic features using Landsat-5/TM data processing techniques on Lesvos, Greece, Geomorphology, 34, 101-109. 
Peña, S. A. ve Abdelsalam, M. G. (2006). Orbital remote sensing for geological mapping in southern Tunisia: implication for oil and gas exploration, Journal of African Earth Sciences, 44, 203-219.

Reilinger, R., McClusky, S., Vernant, P., Lawrence, S., Ergintav, S., Cakmak, R., Ozener, H., Kadirov, F., Guliev, I., Stepanyan, R., Nadariya, M., Hahubia, G., Mahmoud, S., Sakr, K., ArRajehi, A., Paradissis, D., Al-Aydrus, A., Prilepin, M., Guseva, T., Evren, E., Dmitrotsa, A., Filikov, S. V, Gomez, F., Al-Ghazzi, R. ve Karam, G. (2006). GPS constraints on continental deformation in the Africa-ArabiaEurasia continental collision zone and implications for the dynamics of plate interactions. J. Geophys. Res. Solid Earth 111, B05411.

Richards, J. A. (1999). Remote sensing digital image analysis: An introduction, Springer-Verlag.

Richetti, E. (2000). Multispectral satellite image and ancillary data integration for geological classification, Photogrammetric Engineering \& Remote Sensing, 66(4), 429-435.

Rigol, J. P. ve Chica-Olmo, M. (1998). Merging remote-sensing images for geologicalenvironmental mapping: application to the Cabo de Gata-Nijar Natural Park, Spain, Environmental Geology, 34, 194-202.

Rockwell, B. W. ve Hofstra, A. H. (2008). Identification of quartz and carbonate minerals across northern Nevada using ASTER thermal infrared emissivity data, implications for geologic mapping and mineral resource investigations in well studies frontier areas, Geosphere, 4(1), 218246.

Rotherty, D. A. (1987). Improved discrimination of rock units using Landsat Thematic Mapper imagery of the Oman ophiolite, Journal of the Geological Society of London, 144, 587-597.

Salehi, S., Mielke, C., Pedersen, C. B. ve Olsen, S. D. (2019). Comparison of ASTER and Sentinel-2 spaceborn datasets for geological mapping: a case study from North-East Greenland, Geological Survey of Denmark and Greenland Bulletin, 43, e2019430205-01-06.

Sümengen, M. (Derleyen) (2011a). Elazığ - K43 paftası jeoloji haritası. Maden Tetkik ve Arama Genel Müdürlüğü, Ankara.

Sümengen, M. (Derleyen) (2011b). Elazığ - K44 paftası jeoloji haritası. Maden Tetkik ve Arama Genel Müdürlüğü, Ankara.

Şengör, A.M.C. (1980). Türkiye'nin neotektoniğinin esaslarl (Principles of the Neotectonism of Turkey). Türkiye Jeoloji Kurumu Konferans Serisi, Ankara.

Şengör, A. M. C., Görür, N. ve Şaroğlu, F. (1985). Strike-slip faulting and related basin formation in zones of tectonic escape: Turkey as a case study,
In Biddle, K.T., Christie-Blick, N. (Eds.), Strike-Slip Deformation, Basin Formation, and Sedimentation, Soc. Econ. Paleontol. Spec. Publ. Society of Economic Paleontologists and Mineralogists, Oklahoma, 227-264.

Şengör, A. M. C., Lom, N., Sunal, G., Zabcı, C. ve Sançar, T. (2019). The phanerozoic palaeotectonics of Turkey. Part I: an inventory. Mediterr. Geosci. Rev., 1, 91-161.

Şengör, A. M. C. ve Zabcl, C. (2019). The North Anatolian Fault and the North Anatolian Shear Zone, In Kuzucuoğlu, C., Çiner, A., Kazancı, N. (Eds) Landscapes and Landforms of Turkey, Springer, Berlin, 481-494.

Tunay, M. ve Ateşoğlu, A. (2008). Çok zamanlı uydu görüntüleri ile Amasra ve yakın çevresine ait bitki örtüsü değişim analizi, Bartın Orman Fakültesi Dergisi, 10(13), 71-80.

USGS,https://www.usgs.gov/centers/eros/science/ usgs-eros-archive-sentinel-2-comparison-

sentinel-2-and-landsat?qt-

science_center_objects $=0 \#$ qt -

science_center_objects, Accessed date: 30 Temmuz 2020.

van der Meer, F.D., van der Werff, H.M.A., van Ruitenbeek, F.J.A., Hecker, C.A., Bakker, W.H., Noomen, M.F., van der Meijde, M., Carranza, E.J.M., Smeth, J.B. de ve Woldai, T. (2012). Multi- and hyperspectral geologic remote sensing: A review. Int. J. Appl. Earth Obs. Geoinf. 14, 112-128.

van der Meer, F. D., van der Werff, H. M. A. ve van Ruitenbeek, F. J. A. (2014). Potential of ESA's Sentinel-2 for geological applications, Remote Sensing Environment, 148, 124-133.

van der Werff, H. M. A. ve van der Meer, F. D. (2015). Sentinel-2 for mapping iron absorption feature parameters, Remote Sensing, 7(10), 1263512653.

van der Werff, H. M. A. ve van der Meer, F. D. (2016). Sentinel-2A MSI and Landsat 8 OLI provide data continutiy for geological remote sensing, Remote Sensing, 8(11), 883.

Wessel, P., Smith, W. S. F., Scharroo, R., Luis, J. ve Wobbe, F. (2013). Generic Mapping Tools: improved version released, EOS Transactions, American Geophysical Union, 94(45), 409-420.

Yönlü, Ö., Altunel, E. ve Karabacak, V. (2017). Geological and geomorphological evidence for the southwestern extension of the East Anatolian Fault Zone, Turkey. Earth Planet. Sci. Lett., 469, 114.

Zumsprekel, H. ve Prinz, T. (2000). Computerenchanced multispectral remote sensing data: a useful tool fort he geological mapping of Archean terrains in (semi)arid environments, Computers \& Geosciences, 26(1), 87-100. 